\title{
Epidermoid and dermoid cysts of the head and neck region
}

\author{
Samrat S. Sabhalok, Lakshmi S. Shetty, Pallavi H. Sarve, Sneha V. Setiya, Swati R. Bharadwaj \\ Department of Oral and Maxillofacial Surgery, D. Y. Patil Dental College and Hospital, Pimpri Pune 411018, Maharashtra, India.
}

Correspondence to: Dr. Pallavi H. Sarve, Department of Oral and Maxillofacial Surgery, D. Y. Patil Dental College and Hospital, Pimpri Pune 411018, Maharashtra, India. E-mail: drpallavisarve@gmail.com

How to cite this article: Sabhalok SS, Shetty LS, Sarve PH, Setiya SV, Bharadwaj SR. Epidermoid and dermoid cysts of the head and neck region. Plast Aesthet Res 2016;3:347-50.

\section{Article history:}

Received: 27-03-2016

Accepted: 10-10-2016

Published: 04-11-2016

Key words:

Epidermoid cyst,

dermoid cyst,

cystic malformations

\begin{abstract}
Epidermoid cysts, dermoid cysts and teratoid cysts are cystic malformations lined with squamous epithelium. They present as soft nodular lesions with a sessile base. Their prevalence is $7 \%$ in head and neck patients and $1.6 \%$ within the oral cavity. The authors present a case series of 21 patients with dermoid and epidermoid cysts who underwent surgical removal. One year of follow-up was carried out without evidence of recurrence. The removal of these cysts is of great concern as it can cause serious social stigma, aesthetic and functional impairment, dysphagia and dysphonia.
\end{abstract}

\section{INTRODUCTION}

Epidermoid, dermoid and teratoid cysts are cystic malformations lined with squamous epithelium and are classified based on whether they are lined with simple squamous epithelium (epidermoid), or skin adnexa are found in the cystic wall (dermoid), or other tissues, such as a muscle, cartilage and bone are present (teratoid) ${ }^{\left[{ }^{1]}\right.}$ Epidermoid cysts are rare benging lesions usually located in the oral cavity. They present as soft nodular lesions with sessile base. They are frequently found in ovaries and testicles, and less frequently in the head and neck ( $7 \%$ of cases), or within the oral cavity $(1.6 \%){ }^{[1-3]}$ The floor of the mouth is the most commonly affected area, however these cysts can be found in the tongue, lips and buccal mucosa. ${ }^{[4,5]}$ Dermoid and epidermoid cysts of the orbit are described as both superficial and deep formations with most frequently slow intermittent growth. Other than aesthetic effects, during their growth, dermoid and epidermoid cysts can cause disturbances in the eye motility, and in rare cases, also optical nerve compression syndrome. ${ }^{[6,7]}$

Epidermoid cysts occur more frequently in patients between 15 and 35 years but can be seen in all age groups. These are slow growing asymptomatic masses but once they increase in size, they can cause dysphagia, dysphonia and dyspnea. ${ }^{[1]}$ Prior case reports report patients that presented with pain, speech disorder, or respiratory distress due to epidermoid 

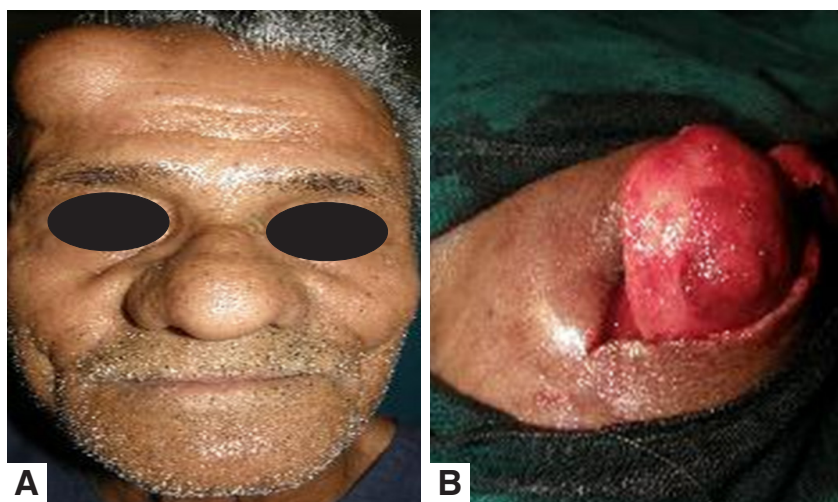

Figure 1: Preoperative $(A)$ and intra-operative $(B)$ view of a dermoid cyst of scalp

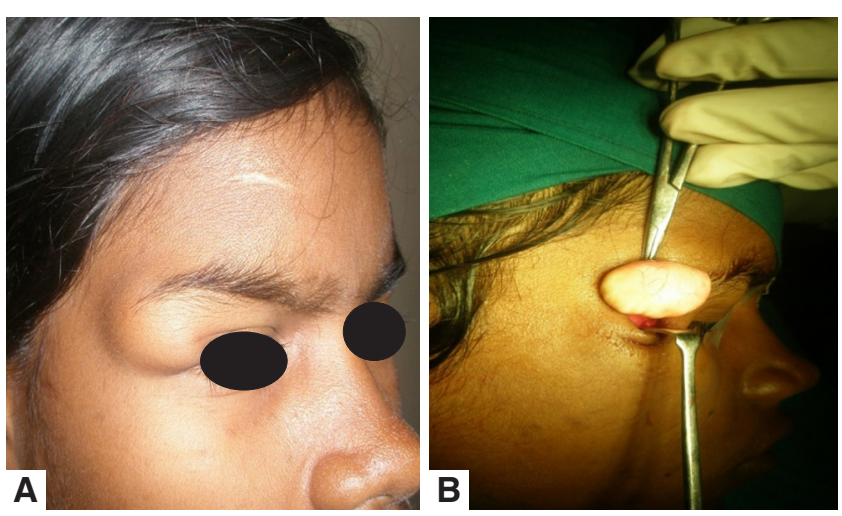

Figure 3: Preoperative $(A)$ and intra-operative $(B)$ view of a dermoid cyst of lateral orbital margin

cyst in the oral cavity, lower lip, or upper lip. ${ }^{[7]}$ Giant epidermoid cysts are rare and they present in the scalp.

Epidermoid cysts are relatively less common in the head and neck region, hence are likely to be misdiagnosed. The aim of this case series is to highlight the presentation of epidermoid and dermoid cysts as a differential diagnosis for head and neck masses, showing various clinical and radiological presentations as well as the surgical outcomes after their removal.

\section{CASE REPORT}

This study included all the patients of dermoid and epidermoid cysts who visited D. Y. Patil Dental College and Hospital, Pune between January 2010 to January 2015. Twenty-one patients ( 12 females and 9 males) were diagnosed clinically with dermoid/epidermoid cyst and confirmed by fine-needle aspiration cytology. Giant cysts were present on the anterior scalp in 5 patients [Figure 1], on the posterior scalp in the occipital region in 3 patients [Figure 2], on the frontal bone in 3 patients, on the lateral orbital margins in 9 patients [Figure 3], and 1 patient had a dermoid cyst intraorally in the upper lip [Figure 4]. The age of the patients ranged

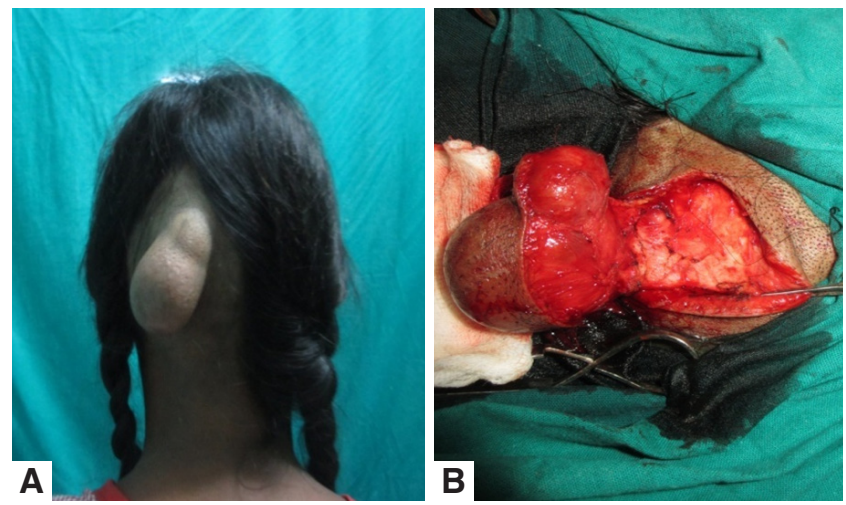

Figure 2: Preoperative $(A)$ and intra-operative $(B)$ view of a dermoid cyst of occiput

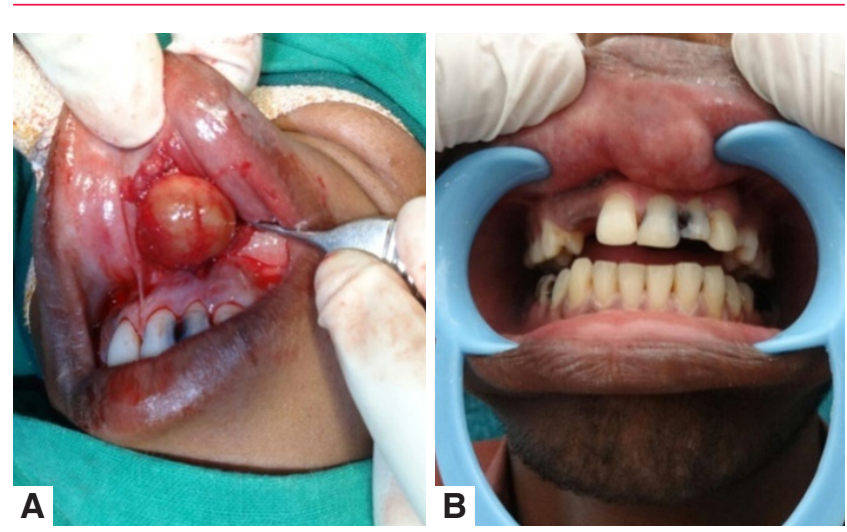

Figure 4: Preoperative $(A)$ and intra-operative $(B)$ view of a epidermoid cyst of the upper lip

16-78 years. The size ranged from $1.5 \mathrm{~cm} \times 2 \mathrm{~cm}$ to $12 \mathrm{~cm} \times 7 \mathrm{~cm}$ [Table 1]. Infected cysts were managed with preoperative antibiotics. All cysts were unilocular. No evidence of malignancy was present. None had recurrence after a minimum 1-year follow-up.

\section{DISCUSSION}

Dermoid cysts have been classified as true dermoid cysts, epidermoid cysts and teratoid cysts..$^{[1-3,6]}$ Several theories have been proposed to explain the development of dermoid cysts: they may result from entrapment of ectodermal tissue of the first and second brachial arches during fetal development; they could represent a variant form of the thyroglossal duct cyst; finally, previous surgical or accidental events could lead to traumatic implantation of epithelial cells into deeper tissues.$^{[1,4]}$ In our case series, we had the presentation of a patient with dermoid cyst in the upper lip region. There are paediatric cases in the literature with epidermal cyst lesions in the sublingual region, gingiva, palate, and uvula. Many of them had history of trauma or surgical intervention. ${ }^{[8]}$ An epidermoid cyst is benign and rarely occurs in the oral cavity. When lesions occur in the floor of the mouth, one must think of other diagnoses including ranula, lymphatic malformation 
Table 1: Characteristics of patients and the cysts

\begin{tabular}{lcccccc}
\hline No. of patients & Age (years) & Gender & Site & Size $(\mathbf{c m} \times \mathbf{c m})$ & Surgery & Follow-up (months) \\
\hline 1 & 21 & Male & Intraoral (upper lip) & $2 \times 2$ & Excision & 13 \\
2 & 35 & Male & Anterior scalp & $1.5 \times 2$ & Excision & 12 \\
3 & 23 & Female & Anterior scalp & $3.2 \times 2$ & Excision & 18 \\
4 & 35 & Female & Posterior scalp & $12 \times 7$ & Excision & 17 \\
5 & 57 & Male & Posterior scalp & $5.5 \times 4$ & Excision & 14 \\
6 & 17 & Female & Lat orbital margin & $2.5 \times 2$ & Excision & 36 \\
7 & 16 & Female & Lat orbital margin & $2 \times 1.5$ & Excision & 25 \\
8 & 22 & Female & Lat orbital margin & $2.2 \times 2$ & Excision & 22 \\
9 & 25 & Female & Lat orbital margin & $2.4 \times 2.2$ & Excision & 30 \\
10 & 24 & Male & Lat orbital margin & $2.5 \times 2.5$ & Excision & 16 \\
11 & 32 & Female & Lat orbital margin & $3 \times 2.8$ & Excision & 14 \\
12 & 36 & Male & Anterior scalp & $3.2 \times 2.8$ & Excision & 19 \\
13 & 23 & Female & Lat orbital margin & $2.2 \times 2$ & Excision & 18 \\
14 & 78 & Male & Frontal bone & $8 \times 5$ & Excision & 20 \\
15 & 62 & Female & Frontal bone & $3.8 \times 3.5$ & Excision & 13 \\
16 & 48 & Female & Frontal bone & $3.2 \times 3$ & Excision & 15 \\
17 & 42 & Male & Anterior scalp & $4 \times 5$ & Excision & 12 \\
18 & 40 & Male & Posterior scalp & $5.5 \times 4$ & Excision & 14 \\
19 & 37 & Male & Anterior scalp & $3.5 \times 3$ & Excision & 14 \\
20 & 32 & Female & Lat orbital margin & $2.5 \times 2$ & Excision & 12 \\
21 & 22 & Female & Lat orbital margin & $2.6 \times 2.2$ & Excision & 18 \\
\hline
\end{tabular}

and heterotypic gastrointestinal cyst. When lesions occur in the tongue, a differential diagnosis of tumor of granular cells, schwanoma, lipoma and neurofibroma, should be considered. When lesions occur in the orbital region, the differential diagnosis of orbital cysts are lipodermoid teratoma, plexiform neurofibroma, encephalocoele, orbital cellulitis, and orbital pseudotumor deep dermoid. ${ }^{[9,10]}$ Thus besides clinical examination, other complementary tests are necessary to achieve a diagnosis and eliminate other diseases. ${ }^{\left[{ }^{[2]}\right.}$ Giant epidermoid cysts are common in females and are usually found on the scalp, in people working outdoors and who have had significant sunlight exposure. On the scalp, it occurs in an area located in a line drawn along the hairline passing through the upper border of the ear lobule and joining these two lines at the occipital area. ${ }^{[11]}$ This is a retention type of cyst and is usually unilocular and contains keratin. Size varies from a few millimetres to a few centimetres but when the size exceeds $5 \mathrm{~cm}$, it is referred to as a giant sebaceous cyst. ${ }^{[11,12]}$ In our case series, giant cysts on the anterior scalp were present in 5 patients and posterior scalp in 3 patients.

Imaging has an important role in confirming the diagnosis and classifying cysts according to their relation to muscle. Ultrasound is the initial imaging modality. Epidermoid cysts are seen as well-defined cysts with multiple welldefined dependent echogenic nodules within the cyst. Computed tomography scan shows a unilocular cyst with homogenous, hypo-attenuating $(0-18 \mathrm{HU})$ fluid material that contains multiple hypo-attenuating fat density nodules giving a "sack of marbles" appearance; this is a feature virtually pathognomonic for a dermoid cyst. Magnetic resonance imaging (MRI) shows fluid signal due to high protein content, and the areas of fat component will show low signal on fat suppressed images. MRI facilitates visualization of the exact location and extent of cystic lesions in the floor of the mouth and is useful for determining their relationship to the surrounding muscles. ${ }^{[3]}$

Pathological features of epidermoid cysts are oily or cheesy, tan, yellow, white material and the cyst wall is a fibrous capsule usually $2-6 \mathrm{~mm}$ in thickness. ${ }^{[3]}$ Total excision is the main treatment for intraoral epidermal cystic lesions since needle aspiration or fenestration might lead to infection, pain, and complaints after treatment. Marsupialisation is another alternative for management of large cysts. ${ }^{[3]}$ Lesions above the mylohyoid muscles are operated on intraorally, whereas those below the muscle are removed via an incision in the neck, ${ }^{[1,13]}$ however, if there is a very large sublingual cyst above the mylohyoid muscle, an extraoral approach may be preferred. An intraoral approach avoids a conspicuous scar, and the recovery time is shorter.

In a study of 103 patients with diagnosis of epidermoid and dermoid cyst of the head and neck, $46.6 \%$ of these were orbital, $23.3 \%$ buccal and submental, $12.3 \%$ nasal, $10.7 \%$ cervical and $2.9 \%$ labial. Various publications also report epidermoid cysts of the oral cavity in the soft palate, the uvula and the sublingual area. However, epidermoid cysts in tonsils are rarely reported. ${ }^{[14]}$ Our case series did not find any epidermoid or dermoid cyst in the tonsillar area. 
The epidermoid cyst rarely discloses malignancy, but isolated cases of premalignant and malignant conditions (Bowen's disease, Paget's disease, and squamous cell carcinoma) have been found in their walls. Ozan et al. ${ }^{[15]}$ and López-Ríos et al ${ }^{[16]}$ described a patient with basal cell carcinoma arising in the wall of an epidermoid cyst. Kronish and Dortzbach ${ }^{[17]}$ presented a case report stating that basal cell carcinoma originated from an epidermoid cyst in which they found nests of basal cell carcinoma connected with the epidermoid cyst. A deep dermoid cyst in the upper eyelid is not generally detected until they increase in size. Precise diagnosis and surgical removal is important because cyst growth can cause proptosis, diplopia and can restrict eye movement. ${ }^{[18,19]}$ Complications of epidermoid cysts of the floor of the mouth include disfigurement, difficulty in swallowing and airway compromise. In addition, it can become infected. ${ }^{[3]}$ In our case series, the most common location of epidermoid cysts was in the lateral orbital region.

In recent literature, we could find no reports related to orbicularis oris muscle fusion defects seconadary to epidermoid cysts. ${ }^{\left[{ }^{[8]}\right.}$ Considering the fact that these kinds of cysts mostly affect children, special caution and care should be applied regarding the precise diagnosis of the type of tumour and its accurate localization. Our case series found only one adult patient with a dermoid cyst located in the orbicularis oris region. The cyst should be completely removed, with minimal trauma and a satisfactory aesthetic effect. ${ }^{[8,17,18]}$

Dermoid cysts may increase in size, leak and cause inflammation, and thus, it is recommended that even asymptomatic cysts should be removed. ${ }^{[19]}$ The reason for early excision is to prevent incidence of secondary infection. The recurrence rate after excision of an infected cyst is $20 \%$ of all cases reported. ${ }^{[20]}$

While dealing with scalp lesions, as well as other cutaneous lesions of the head and neck region, differential diagnosis of keratinous cysts should be kept in mind as these cysts carry certain complications such as cystic rupture, abscess, secondary, and infections, during their treatment. These cysts carry relatively higher risk of recurrence compared to lipomas and certain other benign lesions that mimic these cysts. Therefore, these cysts require thorough histopathological examination and close follow-up due to their potential for malignant transformation. ${ }^{[21]}$ Early diagnosis and removal of dermoid and epidermoid cysts are of great concern as it can cause serious social stigma, aesthetic and functional impairment, dysphagia and dysphonia.

\section{Financial support and sponsorship} None.

\section{Conflicts of interest}

There are no conflicts of interest.

\section{Patient consent}

All involved patients gave their consent forms.

\section{Ethics approval}

This study was approved by the Ethical Review Committee of D. Y. Patil Dental College and Hospital.

\section{REFERENCES}

1. Jham BC, Duraes GV, Jham AC, Santos CR. Epidermoid cyst of the floor of the mouth: a case report. J Can Dent Assoc 2007;73:525-8.

2. Pereira CM, Gasparetto PF, de Lucena Botelho T. Atypical appearance of epidermoid cyst in tongue's ventral surface. RSBO 2011;8:240-2.

3. Mirza S, Fadl S, Napaki S, Abualruz A. Case report of complicated epidermoid cyst of the floor of the mouth: Radiology-histopathology correlation. Qatar Med J 2014;2014:12-6.

4. Elias LSA, Oton-Leite AF, Silva CM, Ribeiro-Rotta RF, Batista AC, de Mendonça EF. Epidermoid cyst: highlights on diagnosis and magnetic resonance imaging features. Rev odonto cienc 2010;25:204-7.

5. Sahoo NK, Choudhary AK. Dermoid cyst of floor of mouth: a case report. Natl J Med Dent Res 2012;1:24-30.

6. Fuchshuber S, Grevers G, Issing WJ. Dermoid cyst of the floor of the mouth--a case report. Eur Arch Otorhinolaryngol 2002;259:60-2.

7. Veselinović D, Krasić D, Stefanović I, Veselinović A, Radovanović Z, Kostić A, Cvetanović M. Orbital dermoid and epidermoid cysts: case study. Srp Arh Celok Lek 2010;138:755-9.

8. Dogan F, Bucak IH. Congenital epidermoid cyst results in muscle fusion defect in the upper lip. Case Rep Otolaryngol 2014;2014:540910.

9. De Ponte FS, Brunelli A, Marchetti E, Bottini DJ. Sublingual epidermoid cyst. J Craniofac Surg 2002;13:308-10.

10. Gandhi N, Syed NA, Alen R. Dermoid cyst. Available from: http:// www.EyeRounds.org/cases/115-dermoid-cyst.htm. [Posted July 26, 2010; Last accessed October 25, 2016].

11. Wani I, Jawaid H, Mir SR, Wani AM, Shah PS, Peerzada AH, Malik S, Teli B, Dar GM. Giant epidermoid cysts. OA Case Rep 2013;2:65.

12. Venus MR, EltiganiI EA, Fagan JM. Just another sebaceous cyst? Ann R Coll Surg Engl 2007;89:1-3.

13. Louis PJ, Hudson C, Reddi S. Lesion of floor of the mouth. J Oral Maxillofac Surg 2002;60:804-7.

14. Erol K, Erkan KM, Tolga D, Bengu C. Epidermoid cyst localized in the palatine tonsil. J Oral Maxillofac Pathol 2013;17:148.

15. Ozan F, Polat HB, Ay S, Goze F. Epidermoid cyst of the buccal mucosa: a case report. J Contemp Dent Pract 2007;8:90-6.

16. López-Ríos F, Rodríguez-Peralto JL, Castaño E, Benito A Squamous cell carcinoma arising in a cutaneous epidermal cyst: case report and literature review. Am J Dermatopathol 1999;21:174-7.

17. Kronish JW, Dortzbach RK. Upper eyelid crease surgical approach to dermoid and epidermoid cyst in children. Arch Opththalmol 1988;106:1625-7.

18. Avakoff JC. Microincision for removing sebaceous cysts. Plast Reconstr Surg 1989;84:173-4.

19. Han HH, Ju RK, Seo BF, Moon SH, Oh DY, Ahn ST, Rhie JW. Dermoid cyst excision under müller muscle in a patient with blepharoptosis. Arch Plast Surg 2014;41:607-9.

20. Dabholkar JP, Patole AD, Sheth AS, Saaj R. Congenital cystic lesions in head and neck. Indian J Otolaryngol Head Neck Surg 2003;55:128-30.

21. Sabhlok S, Kalele K, Phirange A, Kheur S. Congenital giant keratinous cyst mimicking lipoma: case report and review. Indian J Dermatol 2015;60:637. 